\title{
SISTEM RESERVASI TIKET BUS DI TERMINAL ARJOSARI MALANG
}

\author{
Surya Wirawan ${ }^{1}$, Arief Andy Soebroto, Ismiarta Aknuranda \\ Program Studi Teknik Informatika \\ Program Teknologi Informasi dan Ilmu Komputer \\ Universitas Brawijaya Malang \\ ${ }^{1}$ suryawirawan_21@yahoo.co.id,
}

\begin{abstract}
Bus Ticket Reservation System is an application that can be used to help booking bus tickets and the buyer will get a report via SMS Gateway. The reservation system is made by conducting field studies in Arjosari Bus Station Malang. This system uses SMS Gateway to send the report to the buyer after booking bus tickets online. SMS Gateway on this application serves as a liaison which delays sms between External Short Message entitiy (ESME) and Short Message Service Center (SMSC) and so does in reserve.The reservation system made is developed with the PHP programming language and has a prototype system pattern. System functions were tested using the validation testing, performance testing, and usability testing. The results percentage of responses usability testing is 67.7\%. This shows that Ticket Reservation System at Arjosari Bus Station can be used well enough.
\end{abstract}

Key word : SMS Gateway, bus Ticket, Arjosari Bus Station Malang

\section{PENDAHULUAN}

Perjalanan dengan menggunakan alat transportasi darat yaitu bus sangat digemari oleh penduduk Indonesia karena harganya yang terjangkau. Hal ini mendorong para pecinta bus untuk semakin mengembangkan sebuah aplikasi agar dapat membantu kerja manusia atau bahkan melebihi kemampuan kerja manusia. Salah satu penerapannya adalah dalam bidang pemesanan tiket perjalanan menggunakan bus. Umumnya pemesanan tiket bus dilakukan secara manual yaitu langsung mendatangi tempat yang menjual tiket perjalanan bus. Tetapi dengan menggunakan aplikasi ini memudahkan pembeli dalam melakukan pemesanan tiket perjalanan bus. Aplikasi yang dibuat ini adalah aplikasi pemesanan tiket bus untuk membantu dalam melakukan pemesanan tiket bus dan pembeli akan mendapatkan report melalui SMS Gateway. Aplikasi ini dibuat dengan melakukan studi lapangan di
Terminal Arjosari Malang. Pada aplikasi ini menggunakan SMS Gateway untuk mengirimkan report kepada pembeli setelah melakukan pemesanan tiket bus secara online. SMS Gateway pada aplikasi ini berfungsi sebagai penghubung yang melakukan delay SMS antara External Short Message Entitiy (ESME) dan Short Message Service Center (SMSC) serta sebaliknya. Komunikasi antara ESME dan SMS Gateway dapat menggunakan protokol Short Message Peer to Peer (SMPP) atau dengan HTTP, sementara ke SMSC menggunakan SMPP [1].

Proses sistem reservasi tiket bus ini sebagai berikut : calon pembeli yang ingin melakukan transaksi dapat membuka website dan melihat info serta layanan yang tersedia. Jika calon pembeli sudah melihat info keberangkatan bus, proses selanjutnya calon pembeli dapat melakukan pemesanan melalui SMS atau mengisi form pembelian tiket yang telah disediakan. Pemesanan 
melalui SMS dilakukan dengan cara mengirimkan SMS berisikan data data pemesanan tiket bus (nama bus, tujuan, tanggal keberangkatan dan jumlah tiket). Jika data telah diterima maka aplikasi akan mengirimkan pesan kepada pembeli tentang status pemesanan tiket, misal nomer tempat duduk yang diinginkan telah dipesan orang lain, dll. Untuk pemesanan tiket dengan mengisi form dapat dilakukan langsung pada saat calon pembeli membuka website reservasi tiket bus. Jika data yang telah dimasukkan pembeli masuk pada basis data maka pembeli akan mendapatkan pesan bahwa tiket yang dipesan tersedia atau tidak tersedia. Proses pembayaran untuk pemesanan tiket via SMS atau mengisi form pembelian tiket online pada sistem ini dilakukan dengan mengirimkan sejumlah uang sesuai dengan total pembelian ke nomer rekening yang telah disediakan dan calon pembeli harus menyimpan bukti transfer pembayaran sebagai bukti untuk menukar dengan tiket yang sudah dipesan sebelumnya. Dan penelitian ini lebih ditekankan pada penggunaan SMS Gateway dalam aplikasi pemesanan tiket bus secara online.

\section{Dasar Teori}

\subsection{SMS Gateway}

SMS Gateway merupakan pintu gerbang bagi penyebaran Informasi dengan menggunakan SMS. SMS Gateway dapat menyebarkan pesan ke ratusan nomor secara otomatis dan cepat yang langsung terhubung dengan database nomor ponsel saja tanpa harus mengetik ratusan nomor dan pesan di ponsel anda karena semua nomor akan diambil secara otomatis dari database tersebut [2].

\subsection{Gammu}

Gammu adalah sebuah aplikasi crossplatform yang digunakan untuk menjembatani / mengomunikasikan antara database SMS Gateway dengan SMS devices. Aplikasi Gammu berupa daemon yang berjalan secara background [3].

\subsection{Black-Box Testing}

Black-box testing atau behavioral testing berfokus pada persyaratan fungsional perangkat lunak. Pengujian black-box memungkinkan perekayasa perangkat lunak mendapatkan serangkaian kondisi input yang sepenuhnya menggunakan semua persyaratan fungsional untuk semua program [4].

\subsection{Strategi Pengujian}

Strategi untuk pengujian perangkat lunak mengintegrasikan metode desain test case perangkat lunak ke dalam sederetan langkah yang direncanakan dengan baik, dan hasilnya adalah konstruksi perangkat lunak yang berhasil [4].

\subsubsection{Pengujian Validasi}

Pada kulminasi pengujian terintegrasi, perangkat lunak secara lengkap dirakit sebagai suatu paket; kesalahan interfacing telah diungkap dan dikoreksi, dan seri akhir dari pengujian perangkat lunak, yaitu pengujian validasi dapat dimulai. Validasi perangkat lunak dicapai melalui sederetan pengujian black-box yang memperlihatkan konformitas dengan persyaratan. Rencana pengujian menguraikan kelas-kelas pengujian yang akan dilakukan, dan prosedur pengujian menentukan test case spesifik yang akan digunakan untuk mengungkap kesalahan dalam konformitas dengan persyaratan [4].

\subsubsection{Pengujian Performa}

Setelah semua langkah pengujian validasi perangkat lunak secara terstruktur dilakukan, maka perlu dilakukan pengujian sistem di lingkungan dimana dia bekerja untuk mengetahui performa dari perangkat lunak tersebut. Pengujian sistem dirancang untuk menguji waktu kinerja auto-reply dari perangkat lunak SMS Gateway. Pengujian performa melibatkan monitoring pemanfaatan sumber daya dari perangkat lunak yang diuji seperti perangkat lunak pendukung dan perangkat keras. Pengujian performa dilakukan secara spesifik sesuai dengan tipe perangkat lunak yang diuji. Pengujian performa bertujuan untuk mengungkap situasi yang menyebabkan degradasi dan kemungkinan kegagalan sistem [4].

\subsubsection{Pengujian Usability}


Pengujian yang terakhir yaitu pengujian usability. Pengujian usability adalah pengujian terhadap atribut kualitas yang menilai seberapa mudah user interface yang digunakan dalam pengembangan suatu perangkat lunak [5]. Teknik kuisioner dilakukan untuk mendukung pengujian ini. Sampel yang digunakan dalam pengujian ini sebanyak 20 sampel. Pertanyaan yang diajukan dalam kuisioner ini didapatkan dari pihak yang sebelumnya sudah melakukan kuisioner terhadap perangkat lunak berbasis web dengan pengujian usability yang sejenis. Pertanyaan pertanyaan tersebut akan disertakan sebagai lampiran. Pertanyaan kuisioner yang digunakan mengambil referensi dari web : http://balitbang.depkominfo.go.id/ karena pertanyaan kuisioner dari halaman web tersebut dirasa sudah sesuai dan relevan dengan parameter pengujian usability yang akan dilakukan dalam skripsi ini.

\section{METODE PENELITIAN}

\subsection{Studi Literatur}

Studi literatur menjelaskan dasar teori yang digunakan sebagai penunjang dan pendukung penulisan skripsi.

\subsection{Analisa Kebutuhan}

Analisa kebutuhan bertujuan untuk mendapatkan semua kebutuhan yang diperlukan dari sistem yang akan dibangun. Metode analisis yang digunakan adalah Object Oriented Analysis dengan menggunakan bahasa pemodelan UML (Unified Modeling Language). Diagram Use Case digunakan untuk mendeskripsikan kebutuhan-kebutuhan dan fungsionalitas sistem dari perspektif enduser. Analisis kebutuhan dilakukan dengan mengidentifikasi semua kebutuhan (requirements) sistem.

\subsection{Perancangan Sistem}

Perancangan sistem dilakukan setelah semua kebutuhan sistem didapatkan melalui tahap analisis kebutuhan. Perancangan sistem berdasarkan Object Oriented Analysis dan Object Oriented Design yaitu menggunakan pemodelan UML (Unified Modeling Language).
Sebagai Gambaran awal, alur penggunaan sistem dapat dilihat pada Gambar 1

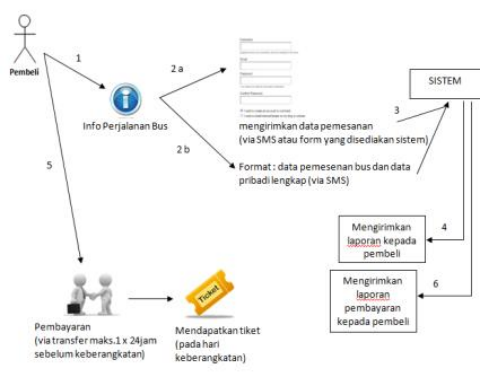

Gambar 1. Diagram Blok Sistem

\subsection{Implementasi}

Dalam implementasi terdapat proses pengkodean. Proses pengkodean atau coding dimaksudkan untuk merealisasikan desain yang telah dibuat secara bertahap dengan memperhatikan alur skenarioskenario yang telah dibuat. Implementasi perangkat lunak dilakukan dengan menggunakan bahasa pemrograman web yaitu PHP.

\subsection{Pengujian dan Analisis}

Pengujian aplikasi dilakukan untuk mengetahui kesesuaian analisis kebutuhan yang dibuat dengan implementasi aplikasi. Proses pengujian dilakukan tahapantahapan yaitu pengujian unit dan pengujian integrasi. Selain itu, dilakukan juga evaluasi sistem terhadap kepuasan konsumen dengan memberikan kuisioner yang dapat diisi langsung oleh konsumen pada aplikasi tersebut. Analisis dari pengujian sistem dilakukan dengan membandingkan hasil-hasil evaluasi dengan persyaratan yang seharusnya dipenuhi oleh sistem.

\subsection{Pengambilan Kesimpulan}

Pengambilan kesimpulan dilakukan setelah semua tahapan perancangan sistem, implementasi, pengujian dan analisis terhadap sistem aplikasi telah selesai dilakukan. Kesimpulan diambil dari hasil pengujian dan analisis terhadap sistem yang dibangun. Tahap terakhir dari penulisan adalah saran yang dimaksudkan untuk memperbaiki kekurangan yang terjadi dan menyempurnakan penulisan 
serta untuk memberikan pertimbangan atas pengembangan aplikasi selanjutnya.

\section{PERANCANGAN}

Proses analisis kebutuhan mengacu pada Gambaran umum perangkat lunak SMS Gateway pada Sistem Reservasi Tiket di Terminal Arjosari Malang dan hasil pengumpulan, pemahaman dan penetapan kebutuhan - kebutuhan yang ingin didapatkan oleh pengguna. Proses analisis kebutuhan ini diawali dengan penjabaran Gambaran umum perangkat lunak SMS Gateway pada Sistem Reservasi Tiket di Terminal Arjosari Malang, identifikasi aktor yang terlibat, analisis data yang akan disimpan, penjabaran tentang daftar kebutuhan dan kemudian memodelkannya ke dalam diagram data flow. Analisis kebutuhan ini bertujuan untuk mengGambarkan kebutuhan - kebutuhan yang harus disediakan oleh sistem agar dapat memenuhi kebutuhan pengguna.

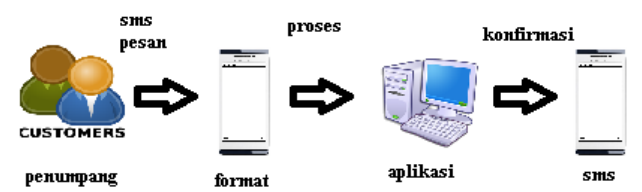

Gambar 2. Sistem Reservasi Berbasis SMS Gateway

Pemodelan diagram use case yang mengGambarkan fungsionalitas Sistem Reservasi Tiket di Terminal Arjosari Malang dibagi menjadi dua yaitu diagram use case untuk aplikasi penumpang dan diagram use case untuk aplikasi admin.

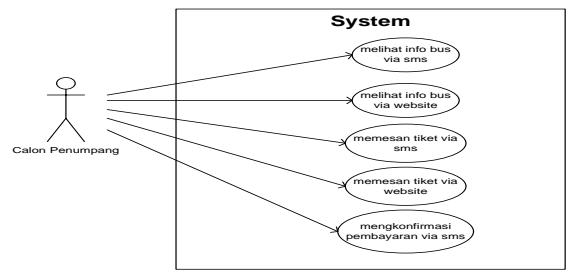

Gambar 3. Diagram Use Case Penumpang

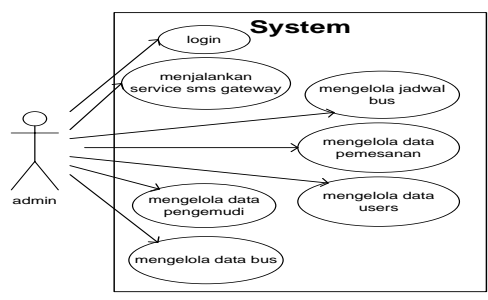

Gambar 4. Diagram Use Case Admin

Perancangan data memiliki dua tahap, yaitu pemodelan dengan Pemodelan dengan DFD dan ERD (Entity Relationship Diagram) .

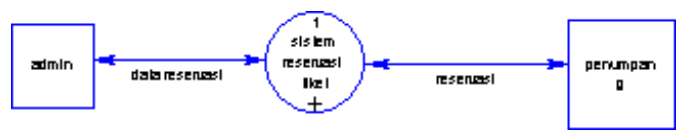

Gambar 5. DFD Level 0 Proses Reservasi Tiket

Basis data berfungsi sebagai tempat menyimpan data. Pemodelan dengan ERD digunakan untuk merancang basis data yang akan dibuat agar masukan dan keluaran program sesuai dengan apa yang diharapkan. Pemodelan dengan ERD mengambil acuan dari proses analisis data yang dilakukan pada tahap analisis kebutuhan.

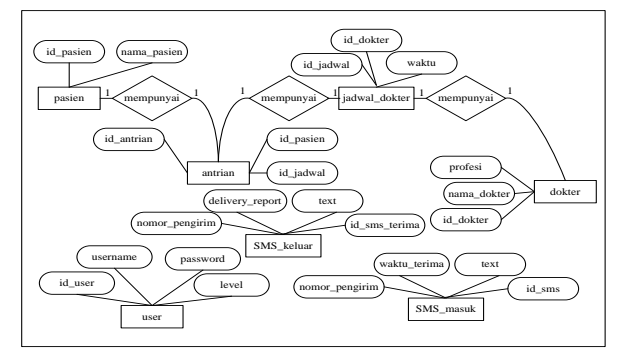

Gambar 6. Diagram entity relationship

\section{IMPLEMENTASI}

Implementasi aplikasi dilakukan dengan mengacu kepada perancangan aplikasi. Implementasi Sistem Reservasi Tiket di Terminal Arjosari Malang dilakukan dengan menggunakan pemrograman struktural yaitu menggunakan implementasi database MySQL dengan software XAMPP 1.7.4 dan bahasa pemrograman Java.

Perangkat lunak SMS Gateway pada Sistem Reservasi Tiket di Terminal Arjosari Malang dibagi menjadi dua subsistem, yaitu subsistem aplikasi penumpang dan subsistem aplikasi admin. 
Antarmuka aplikasi penumpang terdiri dari SMS Melihat Info, SMS Info Bus, SMS Pemesanan Tiket, SMS Konfirmasi Pemesanan Tiket, SMS Konfirmasi Bayar .

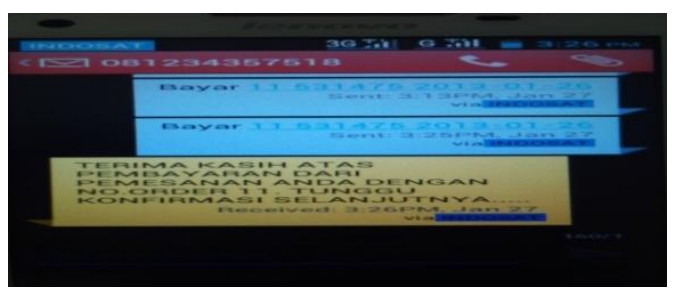

Gambar 7. SMS Konfirmasi Pembayaran Aplikasi Penumpang

Antarmuka aplikasi administrator terdiri dari halaman Login, halaman Home, halaman Run SMS,keluar, halaman Pengemudi, halaman Bus, halaman Jadwal, halaman Pemesanan dan halaman Users.

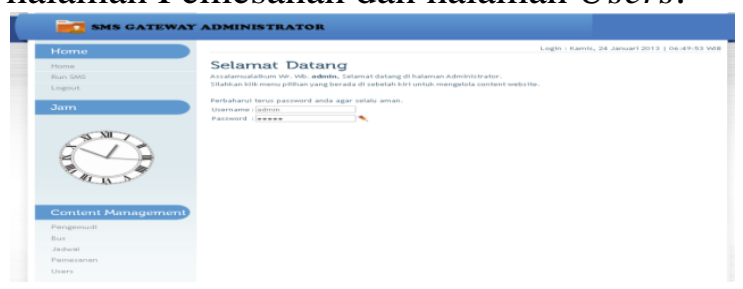

Gambar 8. Halaman Home Aplikasi Admin

\section{PENGUJIAN DAN ANALISIS}

Pada bab ini dilakukan proses pengujian dan analisis terhadap aplikasi perangkat lunak SMS Gateway pada Sistem Reservasi Tiket di Terminal Arjosari Malang yang telah dibangun. Proses pengujian dilakukan melalui dua tahapan (strategi) yaitu pengujian validasi dan pengujian performa aplikasi. Pada pengujian validasi digunakan teknik pengujian Black Box (Black Box Testing). Pada pengujian performa dilakukan dengan menghitung waktu auto-reply SMS menggunakan aplikasi perangkat lunak SMS Gateway pada Sistem Reservasi Tiket di Terminal Arjosari Malang.

\subsection{Pengujian Validasi}

Pengujian validasi digunakan untuk mengetahui apakah sistem yang dibangun sudah benar sesuai dengan yang dibutuhkan. Item - item yang telah dirumuskan dalam daftar kebutuhan dan merupakan hasil analisis kebutuhan akan menjadi acuan untuk melakukan pengujian validasi. Pengujian validasi menggunakan metode pengujian Black Box, karena tidak diperlukan konsentrasi terhadap alur jalannya algoritma program dan lebih ditekankan untuk menemukan konformitas antara kinerja sistem dengan daftar kebutuhan. Pada skripsi ini dilakukan pengujian validasi terhadap perangkat lunak SMS Gateway pada Sistem Reservasi Tiket di Terminal Arjosari Malang.

Tabel 1. Hasil pengujian validasi

\begin{tabular}{|c|c|c|}
\hline No. & Nama Kasus Uji & $\begin{array}{c}\text { Status } \\
\text { Validitas }\end{array}$ \\
\hline 1 & $\begin{array}{l}\text { Kasus Uji Login } \\
\text { Sah }\end{array}$ & Valid \\
\hline 2 & $\begin{array}{l}\text { Kasus Uji Login } \\
\text { Tidak Sah }\end{array}$ & Valid \\
\hline 3 & Kasus Uji Logout & Valid \\
\hline 4 & $\begin{array}{l}\text { Kasus Uji } \\
\text { Menjalankan } \\
\text { Service SMS } \\
\text { GATEWAY }\end{array}$ & Valid \\
\hline 5 & $\begin{array}{l}\text { Mengelola Data } \\
\text { Pengemudi }\end{array}$ & Valid \\
\hline 6 & $\begin{array}{l}\text { Mengelola Data } \\
\text { Bus }\end{array}$ & Valid \\
\hline 7 & $\begin{array}{l}\text { Mengelola Data } \\
\text { Jadwal }\end{array}$ & Valid \\
\hline 8 & $\begin{array}{l}\text { Mengelola Data } \\
\text { Pemesanan }\end{array}$ & Valid \\
\hline 9 & $\begin{array}{l}\text { Mengelola Data } \\
\text { Users }\end{array}$ & Valid \\
\hline 10 & $\begin{array}{l}\text { Melihat Info Bus } \\
\text { Via SMS Sah }\end{array}$ & Valid \\
\hline 11 & $\begin{array}{l}\text { Melihat Info Bus } \\
\text { Via SMS Tidak } \\
\text { Sah }\end{array}$ & Valid \\
\hline 12 & $\begin{array}{l}\text { Melihat Info Bus } \\
\text { Via Website }\end{array}$ & Valid \\
\hline 13 & $\begin{array}{l}\text { Memesan Tiket } \\
\text { Via SMS Sah }\end{array}$ & Valid \\
\hline 14 & $\begin{array}{l}\text { Memesan Tiket } \\
\text { Via SMS Tidak } \\
\text { Sah }\end{array}$ & Valid \\
\hline 15 & $\begin{array}{l}\text { Memesan Tiket } \\
\text { Via Website }\end{array}$ & Valid \\
\hline 16 & $\begin{array}{l}\text { Mengkonfirmasi } \\
\text { Pembayaran Sah }\end{array}$ & Valid \\
\hline 17 & $\begin{array}{l}\text { Mengkonfirmasi } \\
\text { Pembayaran } \\
\text { Tidak Sah }\end{array}$ & Valid \\
\hline
\end{tabular}

\subsection{Pengujian Performa}


Pengujian performa digunakan untuk mengetahui apakah sistem yang dibangun dapat memberikan auto-reply SMS dengan cepat, sehingga dapat memberikan kepastian kepada penumpang dengan cepat pula. Pengujian ini dilakukan dengan menghitung rata-rata lama waktu antara sms yang masuk dengan sms balasan. Pada skripsi ini dilakukan pengujian performa terhadap perangkat lunak SMS Gateway pada Sistem Reservasi Tiket di Terminal Arjosari Malang.

Tabel 2. Hasil pengujian performa

\begin{tabular}{|c|c|c|}
\hline $\begin{array}{c}\text { id } \\
\text { SMS }\end{array}$ & Nomor Pengirim & $\begin{array}{c}\text { Waktu } \\
\text { Tunggu (k - } \\
\text { t) (seconds })\end{array}$ \\
\hline 1 & +6281331166073 & 30 \\
\hline 2 & +6285394559972 & 35 \\
\hline 3 & +6285755676620 & 47 \\
\hline 4 & +6285646477963 & 52 \\
\hline 5 & +628970418907 & 36 \\
\hline 6 & +6285646412251 & 27 \\
\hline 7 & +6285797284663 & 55 \\
\hline 8 & +6285646596965 & 38 \\
\hline 9 & +6285655505963 & 32 \\
\hline 10 & +6285646496611 & 25 \\
\hline 11 & +6285646584080 & 45 \\
\hline 12 & +6285655541353 & 36 \\
\hline 13 & +6281805063617 & 47 \\
\hline 14 & +6287819544335 & 52 \\
\hline 15 & +6282331157795 & 46 \\
\hline 16 & +6283834745261 & 40 \\
\hline 17 & +6282143685055 & 37 \\
\hline 18 & +6281336516651 & 47 \\
\hline 19 & +628170500090 & 51 \\
\hline 20 & +6283848557985 & 34 \\
\hline 21 & +623417000849 & 46 \\
\hline 22 & +6281808000751 & 45 \\
\hline 23 & +6283848557983 & 45 \\
\hline 24 & +6283848557981 & 35 \\
\hline 25 & +6283848557983 & 65 \\
\hline & Total & 41.92 \\
\hline$D a 1$ & Tabel \\
\hline
\end{tabular}

Dari Tabel 2. dapat disimpulkan bahwa waktu tunggu antara SMS masuk dan dibalas oleh aplikasi adalah tidak sama. Dengan melakukan 25 pengujian, maka diperoleh rata-rata waktu tunggu auto-reply SMS dalam aplikasi perangkat lunak SMS Gateway pada Sistem Reservasi Tiket Bus Di Terminal Arjosari Malang adalah 41.92 seconds.

\subsection{Pengujian Usability}

Pengujian usability digunakan untuk menguji kegunaan dari perangkat lunak Sistem Reservasi Tiket di Terminal Arjosari Malang. Pengujian ini ditujukan untuk mengetahui seberapa besar perangkat lunak Sistem Reservasi Tiket di Terminal Arjosari Malang bisa digunakan dengan baik oleh para calon user. Pengujian ini dilakukan dengan cara menyebarkan kuisioner kepada para calon user dan beberapa pegawai P.O bus di Terminal Arjosari Malang. Calon user pada pengujian ini adalah calon penumpang bus di Terminal Arjosari Malang. Pada pengujian ini kriteria - kriteria khusus pada sampel seperti rentang usia, jenis kelamin, dan latar belakang pendidikan diabaikan. Jumlah sampel calon user yang diuji sebanyak 20 sampel.

Tabel 3. Hasil pengujian usability

\begin{tabular}{|c|c|c|c|c|}
\hline No & Komponen & Cukup & Kurang & Tidak \\
\hline 1 & Isi Website & 51 & 26 & 3 \\
\hline 2 & $\begin{array}{l}\text { Ketepatan } \\
\text { informasi }\end{array}$ & 31 & 9 & 0 \\
\hline 3 & $\begin{array}{l}\text { Struktur } \\
\text { Format dan } \\
\text { Desain } \\
\text { Sistem } \\
\end{array}$ & 64 & 35 & 1 \\
\hline 4 & $\begin{array}{l}\text { Ketanggapan } \\
\text { informasi }\end{array}$ & 26 & 13 & 1 \\
\hline 5 & $\begin{array}{l}\text { Sikap } \\
\text { Penggunaan } \\
\text { Sistem }\end{array}$ & 51 & 9 & 0 \\
\hline 6 & $\begin{array}{l}\text { Niat } \\
\text { Penggunaan } \\
\text { Sistem }\end{array}$ & 21 & 15 & 4 \\
\hline & Total & 244 & 107 & 9 \\
\hline
\end{tabular}

Dari hasil pengujian di atas dapat didapatkan 244 jawaban "cukup", 107 jawaban "Kurang" dan 9 Jawaban "Tidak" dengan total semua jawaban 360. Dapat disimpulkan bahwa nilai persentase jawaban "Cukup" sebesar $67,7 \%$.

Tabel 4. Rincian persentase tiap komponen

\begin{tabular}{|c|l|c|}
\hline No & \multicolumn{1}{|c|}{ Komponen } & Persentase \\
\hline 1 & Isi Website & $63 \%$ \\
\hline 2 & Ketepatan Informasi & $77 \%$ \\
\hline 3 & $\begin{array}{l}\text { Struktur Format dan } \\
\text { Desain Sistem }\end{array}$ & $64 \%$ \\
\hline 4 & $\begin{array}{l}\text { Ketanggapan } \\
\text { Informasi }\end{array}$ & $65 \%$ \\
\hline 5 & $\begin{array}{l}\text { Sikap Penggunaan } \\
\text { Sistem }\end{array}$ & $85 \%$ \\
\hline 6 & $\begin{array}{l}\text { Niat Penggunaan } \\
\text { Sistem }\end{array}$ & $52 \%$ \\
\hline
\end{tabular}




\subsection{Analisis}

Proses analisis bertujuan untuk mendapatkan kesimpulan dari hasil pengujian Sistem Reservasi Tiket di Terminal Arjosari yang telah dilakukan. Proses analisis mengacu pada dasar teori sesuai dengan hasil pengujian yang didapatkan. Analisis dilakukan terhadap hasil pengujian di setiap tahap pengujian. Proses analisis yang dilakukan meliputi analisis hasil pengujian validasi, analisis hasil pengujian performa dan analisi hasil pengujian Usability.

Proses analisis terhadap hasil pengujian validasi dilakukan dengan melihat konformitas antara hasil kinerja sistem dengan daftar kebutuhan. Berdasarkan hasil pengujian validasi dapat disimpulkan bahwa implementasi dan fungsionalitas perangkat lunak SMS Gateway pada Sistem Reservasi Tiket di Terminal Arjosari telah memenuhi kebutuhan yang telah dijabarkan pada tahap analisis kebutuhan.

Proses analisis terhadap hasil pengujian performa dilakukan dengan menghitung nilai rata-rata dari waktu tunggu auto-reply SMS. Berdasarkan hal tersebut maka dapat diambil kesimpulan sebagai berikut :

a. Provider dan tempat berpengaruh terhadap lama waktu tunggu auto-reply SMS.

b. Dalam pengujian perangkat lunak SMS Gateway pada Sistem Reservasi Tiket di Terminal Arjosari yang dilakukan pada notebook Sony Vaio VGN CR353, didapat hasil yang baik dengan ditunjukkannya lama waktu tunggu auto-reply yang rata - rata sebesar 41.92 detik.

Proses analisis terhadap hasil pengujian dilakukan dengan melihat nilai persentase jawaban "Ya". Dari 6 komponen pengujian, ada 3 komponen dengan nilai dibawah 65\%, yaitu komponen Isi Website, Struktur Format dan Desain Sistem, dan Niat Penggunaan Sistem dengan nilai masing-masing 63\%, 64\%, dan 52\%.
Dari data kuesioner, pada komponen Isi Website total jawaban "Cukup" sebanyak 51, jawaban "Kurang" sebanyak 26 dan jawaban "Tidak" sebanyak 3. Dari empat pertanyaan yang diajukan, pertanyaan ketiga yaitu "Apakah website ini menyediakan laporan hanya tentang yang anda butuhkan ?" memiliki perolehan jawaban "Cukup" sebanyak 8 jawaban, jawaban "Kurang" sebanyak 10 jawaban dan jawaban "Tidak" sebanyak 2 jawaban. Calon user menginginkan informasi yang lebih detail, update dan mudah dimengerti tentang SMS konfirmasi, data-data bus seperti nama bus, jadwal, tujuan dan nomor tempat duduk. . Inilah yang menyebabkan ada 26 jawaban "Kurang" pada komponen Isi Website. Dari data kuesioner, pada komponen Struktur Format dan Desain total jawaban "Cukup" sebanyak 64, jawaban "Kurang" sebanyak 35 dan jawaban "Tidak" sebanyak 1. Dari lima pertanyaan yang diajukan ada dua pertanyaan yang sama-sama memiliki perolehan jawaban "Kurang" sebanyak 9 dan 11 jawaban "Cukup" yaitu pada pertanyaan "Apakah situs web menyediakan desain yang baik ?" dan "Apakah website ini user friendly (intuitif digunakan) ?". Calon user menginginkan desain website yang lebih menarik agar tidak membosankan. Calon user juga menginginkan ketersediaan informasi tentang panduan pemesanan dan juga pelayanan yang ditawarkan lebih beragam Beberapa calon user juga tidak mencoba untuk menguji sendiri sistem yang sudah disediakan pada saat pengujian. Dua pertanyaan ini menyebabkan 18 jawaban "Kurang" dari total 35 jawaban "Kurang" pada komponen Struktur Format dan Desain.

Dari data kuesioner, pada komponen Niat Penggunaan Sistem total jawaban "Cukup" sebanyak 21, jawaban "Kurang" sebanyak 15 dan jawaban "Tidak" sebanyak 4. Dari dua pertanyaan yang diajukan, pertanyaan kedua yaitu "apakah anda berniat untuk menjadi pengguna setia website ini ?" memiliki perolehan jawaban 
"Cukup" sebanyak 6 jawaban, jawaban "Kurang" sebanyak 12 jawaban dan jawaban "Tidak" sebanyak 2 jawaban. Beberapa calon user masih terbiasa dengan pemesanan tiket secara manual jadi masih terlihat canggung dengan pemesanan tiket secara online maupun via SMS. Inilah yang menyebabkan ada 15 jawaban "Kurang" pada komponen Niat Penggunaan Sistem.

Dari total keseluruhan persentase jawaban, didapatkan nilai $67,7 \%$. Hal ini menunjukkan Sistem Reservasi Tiket di Terminal Arjosari cukup dapat digunakan dengan baik.

\section{KESIMPULAN DAN SARAN}

Berdasarkan hasil perancangan, implementasi dan pengujian yang dilakukan, maka diambil kesimpulan sebagai berikut :

1. Aplikasi Penumpang perangkat lunak pada sistem reservasi tiket di Terminal Arjosari Malang dapat digunakan untuk melihat info bus, memesan tiket bus, dan mengkonfirmasi pembayaran tiket.

2. Aplikasi Admin perangkat lunak pada sistem reservasi tiket di Terminal Arjosari Malang dapat digunakan untuk mengelola data bus dan reservasi tiket.

3. Dalam pengujian perangkat lunak SMS Gateway pada Sistem Reservasi Tiket di Terminal Arjosari yang dilakukan pada notebook Sony Vaio VGN CR353, didapat hasil yang baik dengan ditunjukkannya lama waktu tunggu auto-reply yang rata - rata sebesar 41.92 detik. Provider dan tempat berpengaruh terhadap lama waktu tunggu auto-reply SMS.

4. Dalam persentase jawaban pengujian usability, didapatkan nilai $67,7 \%$. Hal ini menunjukkan Sistem Reservasi Tiket di Terminal Arjosari cukup dapat digunakan dengan baik.

Saran yang dapat diberikan untuk pengembangan perangkat lunak ini antara lain :
1. Disarankan memilih provider untuk server yang memiliki traffic kecil.

2. Dapat ditambahkan beberapa fitur seperti pemilihan nomor tempat duduk dan pedoman pemesanan tiket bagi user dalam sistem reservasi tiket bus.

3. Disarankan untuk memberikan keamanan backup data antrian untuk setiap harinya.

4. Disarankan untuk memperbaiki desain dan tampilan web agar lebih menarik minat user.

5. Disarankan untuk menyediakan informasi yang lebih detail, terkini dan mudah dimengerti tentang SMS konfirmasi, data-data bus seperti nama bus, jadwal, tujuan dan nomor tempat duduk.

\section{DAFTAR PUSTAKA}

[1] Murtadlo, Ali \& Arifin, Firman \& Setiawardhana. 2011. Simulasi Sistem Informasi Posisi Kereta Api dengan Menggunakan GPS untuk Keselamatan Penumpang. Surabaya : Institut Teknologi Sepuluh November.

[2] Ramadhika A. 2012. SMS Gateway menggunakan Gammu dan MySQL. http://www.ubaya.ac.id/ubaya/articles _detail/33/SMS-Gatewaymenggunakan-Gammu-danMySQL.html.

[3] Pressman, Roger S. 2010.Software Engineering : A Practitioner's Approach, Fifth Edition. McGraw Hill.

[4] Nielsen, Jakob. 2003. Usability 101 : Introduction to Usability. Akses dari http://faculty.wiu.edu/CBDilger/f07/480/readings/10-nielsenusability-101.pdf. 